\section{A QUALITATIVE EMPIRICAL INVESTIGATION OF CONTRIBUTING SUCCESS FACTORS FOR SOFTWARE TESTING OUtSOURCING PROJECTS}

\author{
Fatin Filzahti Ismail*, Rozilawati Razali
}

Centre of Software Technology and Management, Faculty of Information Science and Technology, Universiti Kebangsaan Malaysia, 43600 Bangi, Selangor, Malaysia
Article history

Received

2 February 2015

Received in revised form

8 October 2015

Accepted

12 October 2015

*Corresponding author filzahti89@gmail.com

\section{Graphical abstract}

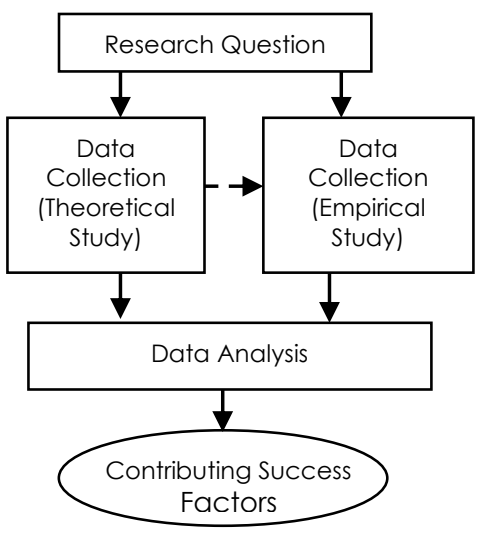

\begin{abstract}
Software testing outsourcing is becoming attractive among organisations that desire to gain high quality products within reasonable cost while allowing testing experts to assure its quality. Despite these promising advantages however, organisations have yet to learn the factors that contribute to such projects' success. The necessary planning and actions could not thus be taken towards the effort. Consequently, software testing outsourcing projects still fail. This study aimed to address this concern by collating the factors from previous research. The investigation continued by confirming the factors besides discovering other relevant factors from software testing practitioners. This study adopted qualitative approach where it employed semi-structured interviews involving five practitioners, who represented both client and vendor. The data were analysed using content analysis. The results show that there are two aspects to be considered, namely Process and People. The former contains nine factors and the latter comprises four factors. Each factor has specific elements, which delineates the characteristics or roles that it owns. The findings provide practitioners with understanding of conducting software testing outsourcing projects effectively.
\end{abstract}

Keywords: Software testing, outsourcing, empirical assessment

\begin{abstract}
Abstrak
Pengujian perisian secara penyumberan luar semakin menjadi tarikan kepada organisasi yang ingin mendapatkan produk perisian yang berkualiti tinggi dengan kos yang munasabah. Walaupun kelebihannya menyakinkan, organisasi masih tidak mengetahui faktor yang menyumbang kepada kejayaan projek seumpamanya. Oleh itu, perancangan dan tindakan sewajarnya tidak dapat diambil ke arah usaha tersebut. Akibatnya, projek pengujian perisian secara penyumberan luar masih gagal. Kajian ini bertujuan untuk menangani permasalahan ini dengan mengumpul faktor kejayaan daripada penyelidikan sebelumnya. Kajian diteruskan dengan mengesah faktor tersebut selain menemui faktor lain yang berkaitan daripada pengamal industri pengujian. Kajian ini menggunakan pendekatan kualitatif iaitu temu bual separa berstruktur melibatkan lima pengamal industri yang mewakili pelanggan dan pembekal. Data dianalisis dengan menggunakan analisis kandungan. Hasil kajian menunjukkan terdapat dua aspek yang perlu diambil kira iaitu Proses dan Manusia. Aspek Proses mengandungi sembilan faktor manakala Manusia terdiri daripada empat faktor. Setiap faktor mempunyai unsur tertentu yang menggariskan ciri atau peranan yang dimilikinya. Hasil kajian ini memberi pemahaman kepada pengamal industri untuk mengendali projek pengujian secara penyumberan luar dengan berkesan.
\end{abstract}

Kata kunci: Pengujian perisian, penyumberan, penilaian empirik

(C) 2015 Penerbit UTM Press. All rights reserved 


\subsection{INTRODUCTION}

Software has become pervasive in the current business environment and society. A mishap in one particular business function due to software failure may cause unbearable losses to organisations. As such, it is imperative to test software systems exhaustively before they are put into operations.

Software testing is a process of ensuring a program, product or service to perform its functions correctly according to the intended context [1],[2]. As a part of software life cycle, software testing is executed by the development team members themselves, particularly testers. Due to resource and time constraints however, it is quite common for software testing to be delegated to external parties. Such arrangement is called software testing outsourcing.

As the testers are totally independent parties, the testing process is more natural, neutral and focused without being influenced by the development team and organisation. Thus, a higher quality software can be expected [5]. Despite the fact that software testing outsourcing is a promising initiative, yet some projects did still fail [6]. The projects exceeded the deadlines and budgets as well as did not meet the expectations. This phenomenon is definitely worrying, which root causes are yet to be discovered. Consequently, there is a need to recognise the important factors that contribute to the success of software testing outsourcing. Until that understanding is obtained, such project failures would continue to exist.

This paper aims to shed some light on the issue by collating the contributing factors from theoretical and empirical perspectives. The factors were originally gathered from literature as a conceptual process model [7]. The model was then carried forward to an empirical study involving five practitioners from software testing industry. The purpose of the empirical study was to confirm the earlier factors as well to collect any new emergent factors. The empirical investigation was conducted qualitatively in order to gain better insights about the phenomenon. This approach was chosen as it provides a strategic menchanism to obtain the views and perspectives of the people who are involved directly in the subject matter.

The paper is organised as follows. Section 2 discusses the related work on software testing outsourcing. Section 3 elaborates the methodology used in collecting and analysing the data. Section 4 presents the findings of the work. Finally, Section 5 discuss the results and concludes the paper by outlining the main findings and future work.

\subsection{RELATED WORKS AND BACKGROUND}

Software testing outsourcing concerns delegating testing operations to external testing teams on a contract basis in a stipulated period of time. In comparison to conventional testing, it offers a wide variety of benefits, namely improving quality through skilful workforce and allowing organisations to focus on development activities by handing over the testing business to experts [4], [5].

Even though the advantages are intriguing, not all organisations should opt for software testing outsourcing. Organisations need to assess the criticality of conducting testing via outsourcing by understanding its nature [8]. They must have concrete reasons and purposes before pursuing the effort, as ambiguous objectives normally lead to project failures [9], [10]. In general, organisations choose outsourcing due to cost, resource and knowledge constraints [8], [11]. An organisation would normally consider outsourcing if they lack of the required resources, skills and knowledge for testing or the development cost could be more optimised by assigning the testing effort to vendors.

When the decision to outsource has been made, the client must plan the strategies to anticipate any risks [12]. The planning includes defining scope of work [9],goals and objectives, specifying the required testing tasks and types [3], [4], priorities [3], [13], determining the types of artifacts to be sent for outsourcing [3] and estimating the budget [12], schedule and resource allocation [3], [12]. Scope should also be defined clearly, to avoid unclear statement of work and cause project failures [9], [13]. The infrastructure that should be established for the project must also be considered in the planning. This includes network and connection setup [3], control for work products [14], [15], storage and information security policies [3], [8], [12].

Vendor analysis should be conducted in order to assess the potential vendors' capabilities and reputation. The testers in vendor organisation should possess technical as well as domain knowledge. Previous studies have indicated that good technical skills and deeper understanding of domain requirements contribute to better testing quality [4], [8], [16]. The testers must be sufficient and available throughout the project as any interruption of workforce will cause extra workload, affect the product quality and drag the process [3], [4]. Political stability, language and culture also influence the outsourcing ecosystem especially when it involves organisations from different countries. Political issues include organisational politics [17], [18] as well as political situation of the vendor's country [12], [10]. Political disturbance either in vendor's organisation or country may prolong the project duration [12]. Misinterpretation in language could cause miscommunications between client and vendor, and later jeopardise the cooperation between them [3], [4], [19]. Incompatibility and difference in culture would affect the smooth running of software testing outsourcing projects [20]. Culture entails behavior patterns that are influenced by specific beliefs and assumptions. As such, culture and language are among the highest barriers in offshoring outsourcing [19]. High turnover rate also influences vendor selection, as it may cause project loss due to 
resignation of experienced testers during the project [3], [4], [12].

The contract formalises the project planning in a written legal-binded document which definitely needed in ensuring the agreed aims are achieved. As technology keeps on evolving over time, the contract should be flexible [8], [21], in short-term basis to allow regular reviewing [8] and should be aligned with the strategic purpose of outsourcing so that both risk and reward could be handled with the right balance [11]. The contract must define clearly the scope, objectives, schedule and statement of work for the testing, which are approved by the parties involved [3], [10]. Both vendor and client should abide terms and conditions declared in the contract [10]. Statements regarding budget and authority should not be vague so that any misunderstanding could be averted [3]. Even if the contract could act as a bail in a joint venture, outsourcing is expected to be more successful if partnership values exist among parties involved [16], [21], [22].

Outsourcing requires client and vendor to nurture partnership values and trust so that pleasant and cooperative environment could be built [23], [24], [25], [26]. The process could be streamlined if good communication, commitment, understanding and tolerance between the team members are practiced [10]. Managing the vendor through fostering good relationships is imperative [8], [23]. Knowledge transfer between the parties involved is also important [27]. Better information flow could be achieved by cultivating effective communication and enhancing the ability to coordinate well between parties involved [3], [28], [29], [30].

Without an adequate network infrastructure such as firewall granting, internet connectivity and network security, it is impossible to provide connectivity between the parties involved [12]. Connectivity concerns the communication channels between client and vendor for sharing and exchanging information purposes. This includes email, telephone call, virtual meeting and instant messaging [14]. Information security measures also need to be setup to protect information confidentiality issues [8]. As testing activities are situated at different locations in outsourcing, it is essential to provide a dedicated storage for archiving and distributing the artifacts produced during the project [14], [15]. Version controls need to be imposed in order to keep track the artifacts produced throughout the project [14]. A toolset for test standardisation methods could be proposed to improve the testing performance [14], [31]. Infrastructure needs to be handled properly by both parties in order for the project to run smoothly [3].

Established infrastructure alone is insufficient to ensure the smooth running of outsourcing without proper work monitoring by client. Monitoring is crucial in ensuring the assigned work and the standards that have been set for vendor are properly followed and managed [3], [23]. Some examples of monitoring include on-going discussions [3] and regular reminders regarding project objectives [4], routine visits and updates of work progress [28] as well as onsite representative [3]. By monitoring, any issues that arise could be detected and handled right away before they become worst.

After the testing activities has been completed, the testing outcomes are evaluated through quality assessment in order to determine whether or not the project objectives are met [32]. The client has the right to reject the outcomes, particularly if they do not meet the stipulated criteria or expectation. Project artifacts such as tools, test logs, defect analysis, test results and test cases need to be returned to the client by virtue of their ownership of those materials. The final test report that contains the status of the entire testing project must also be provided by the vendor [15]. These activities and outcomes are then used as the measures to evaluate the vendor performance. This assessment may influence the vendor selection process in future testing projects [15].

Management aspect also plays an important role in software testing outsourcing. Project manager needs to ensure the continuity of the project as the outsourcing process may involve long distances, different culture, language and time zone. In order to overcome cultural differences and geographical distance, project manager should impose team coordination and collaboration [33] through team building and cooperation spirit [34], [35]. Project managers should be credible in ensuring the project milestones are met and handling any occurring disparity throughout the project. Top management also should also support the project by ensuring it progresses according to the organizational objectives. As direction and resources provider, the role of top management is essential for the project continuation [10].

\subsection{RESEARCH METHODOLOGY}

The primary objective of this study was to confirm empirically the contributing success factors of software testing outsourcing, which were gathered from literature and reported in [7] as a conceptual process model previously. This study extended the earlier theoretical work by conducting an empirical work involving experienced practitioners from software testing industry. The practitioners' viewpoints are necessary in order to confirm the existence and practicality of the factors in real world settings together with elaboration on the elements involved. In addition, the study was also intended to collate any other factors from practitioners, which were not identified in the literature. Figure 1 illustrates the research design, which contains the main activities involved in the study.

a) Research Questions Formulation

The study aimed to answer the following research questions. The questions were generated based on a preliminary study made on the subject matter, which 
acted as the basis for data collection during theoretical and empirical studies.

What are the contributing success factors of software testing outsourcing projects? What are the specific elements for each of these factors?

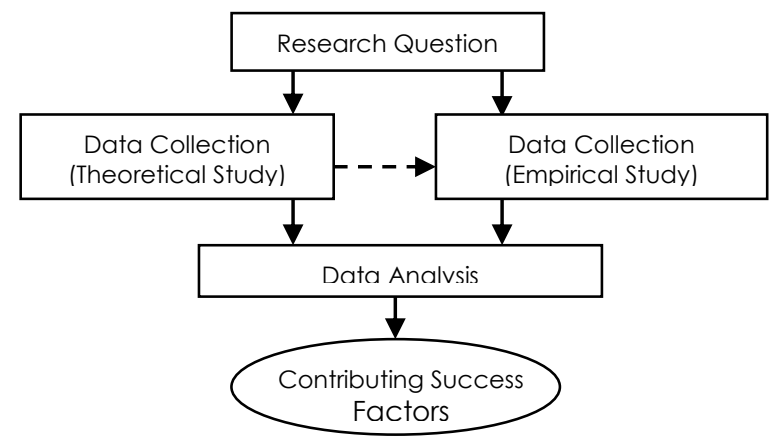

Figure 1 Research Design

b) Theoretical Study

This study was conducted by analysing the existing literature. The aim of this study was to identify the contributing factors of successful software testing outsourcing discovered by previous studies. The findings of the study can be found in [7].

c) Empirical Study

To answer the above research questions, a series of individual face-to-face interviews with practitioners from software testing industry was conducted. Such approach was chosen because it allows a deeper understanding on a specific matter based on individual views, experiences, beliefs or motivations [36]. The study used semi-structured interviews, which delineate specifically the key areas to be explored but yet allow the participants to deviate to other relevant areas in more details, if required. As a qualitative research, the study employed convenience and purposive sampling method. The sampling was convenient because the chosen participants represented a small portion of subjects that were approachable to the researchers. The participants were purposive because they fulfilled the required criteria set up by the study. The criteria used were the participants must possess at least 5 years of experience in software testing outsourcing projects. They include testers and test leaders from the vendor side as well as project managers and members from the client side. The potential participants may represent private or public sector.

The interview questions were derived based on the conceptual process model outlined in [7]. Before performing the actual interviews, the planned protocol and instruments were tested in a pilot study. The purpose of the pilot study was to ensure the questions conferred during interviews were relevant and the protocol was feasible. Later, the identified potential participants were contacted and invited officially to the sessions. After obtaining the participant's agreement, the interview was conducted on the agreed day, time and venue.

The interviews were conducted between June 2014 and January 2015 with participants from both public and private sectors. There were five participants involved in the study: two people from public sector and three people from private sector. The participants were interviewed individually at their respective workplace within approximately two hours. The duration was considered to be sufficient due to the need to compromise between coverage and the amount of time that the participants could spare. Table 1 briefly outlines the participants' profiles. Before beginning the session, the participants were briefed about the purpose of the study and their roles as participants. Upon obtaining participants' consent, each session was audio-taped for reviewing and transcribing purposes. Besides that, field notes were also made during the sessions, which act as additional information about intensity of comments, facial expressions and other facets of interpersonal communication. The data were then transcribed and stored for analysis and interpretation.

The following paragraphs elaborate in detail the activities involved during data collection for the empirical study and the data analysis

Table 1 Participants' Profiles

\begin{tabular}{|c|c|c|c|c|c|}
\hline Criteria & Position & $\begin{array}{l}\text { Service } \\
\text { (Years) }\end{array}$ & $\begin{array}{c}\text { Testing } \\
\text { Domain } \\
\text { Experience } \\
\text { (Years) }\end{array}$ & Sector & Business Domain \\
\hline Informant 1 & $\begin{array}{c}\text { Information } \\
\text { Technology Officer }\end{array}$ & 6 & 6 & Government & Electronic Government Systems \\
\hline Informant 2 & System Developer & 6 & 6 & Government & Electronic Government Systems \\
\hline Informant 3 & Software Tester & 5 & 5 & Private & Application Systems \\
\hline Informant 4 & Test Lead & 7 & 7 & Private & Banking Systems \\
\hline Informant 5 & $\begin{array}{c}\text { Test } \\
\text { Manager/Lead }\end{array}$ & 9 & 6 & Private & Application Systems \\
\hline
\end{tabular}


Table 2 Interview Questions

\begin{tabular}{|c|c|}
\hline Factor & Description \\
\hline $\begin{array}{c}\text { Need } \\
\text { Identification }\end{array}$ & $\begin{array}{l}\text { To affirm whether purpose, reasons and understanding of outsourcing influence the success of software } \\
\text { testing outsourcing projects. }\end{array}$ \\
\hline $\begin{array}{l}\text { Project } \\
\text { Planning }\end{array}$ & $\begin{array}{l}\text { To confirm whether project planning is important before executing software testing outsourcing projects. } \\
\text { The planning aspects include setting the goals and objectives, determining artifacts and types of testing, } \\
\text { risks, scope and statement of work, budget plan, priorities, infrastructure, resource allocation and } \\
\text { scheduling. }\end{array}$ \\
\hline $\begin{array}{l}\text { Vendor } \\
\text { Selection }\end{array}$ & $\begin{array}{l}\text { To confirm whether the selection criteria are crucial in selecting the right vendors for software testing } \\
\text { outsourcing projects. } \\
\text { The criteria embrace domain and technical expertise, reputation, sufficient resources, political stability, } \\
\text { language and culture as well as turnover rate. }\end{array}$ \\
\hline $\begin{array}{l}\text { Contract } \\
\text { Establishment }\end{array}$ & $\begin{array}{l}\text { To substantiate the required characteristics of the contract established in software outsourcing projects. } \\
\text { The characteristics comprise clear and complete contract where the work scope for both parties, } \\
\text { statement of work, budget, schedule and authority are specified succinctly. The contract is likely to be in } \\
\text { short term basis, flexible and aligned with the stated project needs and plan. }\end{array}$ \\
\hline $\begin{array}{l}\text { Infrastructure } \\
\text { Setup }\end{array}$ & $\begin{array}{l}\text { To confirm whether setting-up the environment for testing outsourcing projects is imperative. } \\
\text { The infrastructure Includes network and connectivity, information security as well as storage and testing } \\
\text { standardisation tools. }\end{array}$ \\
\hline $\begin{array}{l}\text { Project } \\
\text { Monitoring }\end{array}$ & $\begin{array}{l}\text { To verify whether regular visits, progress reports, discussion, reminders and on-site representative are } \\
\text { necessary during the execution of testing phase. }\end{array}$ \\
\hline $\begin{array}{c}\text { Quality } \\
\text { Assessment }\end{array}$ & To confirm whether it is important to assess the testing quality after the process was completed. \\
\hline $\begin{array}{l}\text { Project Close- } \\
\text { Out }\end{array}$ & $\begin{array}{l}\text { To verify whether vendor assessment, version control setup and project artifacts handover are necessary } \\
\text { during the project close-out and how they contribute to the success. }\end{array}$ \\
\hline People & $\begin{array}{l}\text { To affirm how the following roles specifically impact software testing outsourcing projects: } \\
\text { - Top management should give full commitment as they play an important role in establishing the } \\
\text { needs, ensuring proper planning and execution of the projects. } \\
\text { Project manager should possess good interpersonal skills in order to coordinate plan, deal with } \\
\text { other parties and must also ensure the project progresses according to the project objectives. } \\
\text { - Team members should cooperate, commit, tolerate, understand, trust and communicate well } \\
\text { with each other besides allowing good partnership and relationship as well as transferring } \\
\text { knowledge. Software testers who are a part of team members should possess technical and } \\
\text { domain knowledge to produce high quality testing results. }\end{array}$ \\
\hline
\end{tabular}

\subsection{Data Collection}

As the study employed semi-structured interviews, the participants were initially asked based on the previously identified factors. To ease the understanding, the participants were given the conceptual process model of software testing outsourcing derived in [7] during the interviews. The participants were required to scrutinise the model and confirm the validity of the factors according to their knowledge and experience in software testing outsourcing industry. At the same time, they were highly encouraged to suggest new factors or elements, which are necessary to be included in the model. They were also asked to reject any factors or elements that are not relevant. The interview questions were revolved around nine factors, which are Needs Identification, Project Planning, Vendor Selection, Contract Establishment, Infrastructure Setup, Project Monitoring, Vendor Assessment, Project Close-Out and People. The nine factors included in the interview questions are summarised and described in Table 2.

\subsection{Data Analysis}

The data gathered from the interview sessions were analysed by using content analysis [37]. Content analysis was used to identify and categorise success factors that contribute to software testing outsourcing. The method was chosen as it allows the identification of significant themes from the participants' responses in terms of existence, frequency and relations between keywords and concepts. The analysis was initiated by the coding procedure, which gave a label to each text segment. A text segment may range from few words to a paragraph. The coding rearranged and integrated the related words, sentences or paragraphs together in order to draw a meaningful description about the data. The data then formed a specific theme. In this study, the themes are indeed the factors that contribute to the success of software testing outsourcing. The factors that have been identified were categorised as manifest and latent content. Manifest content is the literal meaning of the content whereas latent content is the underlying meaning behind the message. In order to determine both manifest and latent content, inductive and deductive reasoning were used. The deductive 
reasoning was established by using the factors and elements identified in the theoretical study as the theories to be confirmed or refuted by the empirical data. The inductive reasoning was done by recognising new emergent data from the empirical study, which were either then grouped into the existing factors or elements, or abstracted as new ones. To strengthen the validity of the new emergent elements, they were reconfirmed by revisiting the literature. The proses were carried out continuously throughout the analysis.

\subsection{RESULTS}

The results obtained were divided into two categories, which are Process and People as tabulated in Table 3 and Table 4 respectively. Table 3 lists the contributing success factors concerning the activities involved in software testing outsourcing process. Meanwhile, Table 4 outlines the contributing success factors in terms of the people involved in the process. These factors are collated and confirmed from theoretical and empirical perspectives.

Each contributing success factor constitutes the corresponding success elements. The elements that were present in the theoretical and/or empirical data are marked with (/). In contrast, the elements that were not supported by theoretical or empirical data are marked with $(X)$. The numbers in the brackets represent the number of participants who approved or advocated the existence of the data. For example, 2/5 means two out of five participants agreed on the element.

The Process category consists of nine contributing success factors of software testing outsourcing during project progression. The factors are Needs Identification, Project Planning, Vendor Selection, Contract Establishment, Testing Phase Preparation, Infrastructure Setup, Project Monitoring, Quality Assessment and Project Close-Out. Eight factors were originated from the theoretical study and confirmed by the empirical study. There is one new emergent factor derived from the empirical study, which is Testing Phase Preparation. The following paragraphs present the results of data analysis together with the interpretation. To support the claims, some excerpts of the actual interview responses are provided. The bold text indicate the elements pertaining to the respective factors.

\subsection{Identifying Needs}

During Need Identification, the client needs to identify the reason and purpose of pursuing outsourcing as well as understand the nature of outsourcing before initiating any software testing outsourcing project. The top management defines the purpose based on known reasons, which directs the expected outcomes of the project. The purpose is generally because of the need to produce high quality software particularly that involves critical functions or transactions. Some possible reasons may be due to resource, knowledge or cost constraints. As an outsourcing project is not quite the same as a conventional project, the client must be aware of its underlying strengths, limitations, requirements, risks and expectations. The participants agreed that the purpose of outsourcing needs to be articulated beforehand.

Most systems in government involve critical functions with important transactions. We need to make sure that the systems cannot have any problem. It must be 0.001 errors. It is crucial to avoid error or malfunction. - Informant 1

We implement testing outsourcing because we need it, there is an urgency in doing it, or it is a requirement from the upper management to do the outsourcing. If there is no demand to outsource testing especially from the upper people, then there is no need to do the outsourcing. - Informant 2

Usually we are given the key elements or what we need to obtain from such testing. Based on that purpose, we will achieve the testing objectives. Informant 3

For clients, the purpose is to ensure that the software produced meets the quality standards. It is necessary for the software to function as it should be. Informant 5

Organisations normally choose to outsource software testing because they need to have the access to better testing equipment and experts as well as having an independent testing. These reasons were specified by the participants.

Usually, we go for outsourcing because we do not have the technical expertise here. So, we need those external people as they have better equipment and knowledge. - Informant 1

We do not have the expertise to do the testing comprehensively even though we have the budget for the project. That is the reason why we go for outsourcing. - Informant 2

The reason why clients hire vendors to do the testing is because they want to find other failures in the product that they did not expect. For clients that develop their own software, they normally have their own QA team. But to avoid bias, they will hire external parties to do the testing. - Informant 3

The reason is that clients now realise the need and importance to do software testing, especially for high impact projects. Besides, testing vendors have the required tools to do the testing. - Informant 5

Understanding the nature of outsourcing is important as it helps the top management to judge whether or not the decision to outsource would bring benefits to the organisation. It also enables the management to assess and manage the risks better. The participants delineated these facts.

We have to understand the outsourcing process and the procedure to be taken, together with the risks and benefits to implement it. Before deciding for 
outsourcing, upper management needs to carefully decide whether it is worthwhile or not. - Informant 2 The product risk can be transferred to the vendor. If a company tests its own product, it will bear the risk entirely. However, if it splits the testing to several vendors, the risks can be reduced. Thus, it is important to understand outsourcing nature to retain the company competitiveness. - Informant 3

\subsection{Planning the Project}

Project planning covers the essential elements that need to be emphasised in designing plans for software testing outsourcing projects. This includes setting the goals and objectives for the project, defining the testing types and artifacts, preparing the contingency plan to avoid possible risks, specifying the scope for statement of work, allocating resources and budget, determining task priorities, project scheduling and identifying the infrastructure needed for the project. The participants confirmed that setting the goals and objectives is important in guiding software testing outsourcing projects.

The project plan must state exactly our targets in performing the outsourcing, what we want to outsource and what we want to achieve. Everyone involved thus knows clearly what we are aiming before executing the plan. - Informant 1

We could not carry out a project without clear goals and objectives that we need to achieve. -Informant 2

We will have a meeting to specify and discuss the goals and objectives to achieve. Our goal is to make sure that there would be fewer defects. We know that the defects would still occur, but our goal is to make sure that the defects are less than expected. Informant 3

Every project plan must state the project goals and objectives. It defines why the project is being executed, what the expectations are and ensures everyone involved has the common goals. The vendor then knows what the client expects and wants for the project. The work resources and time could be estimated to meet with the client's needs. - Informant 4

The participants approved that defining the types of testing required as well as the artifacts that could be given to the vendor is an important factor in the planning process. The suitable artifacts are carefully determined before they can be prepared and given to the vendor.

It is a mandatory step to ensure that we do not provide information that should not be provided. We will isolate the data from the requirements. By that way, the original data are preserved. If the vendor requires any other information that we do not provide, we will give that information separately. Thus, we audit the information needs. - Informant 2

We have to be careful in selecting the testing items because not every type of testing is suitable to be outsourced, as data for government systems are highly sensitive. - Informant 1

Vendors normally conduct regression test, security test or performance test. Clients should consider what they want to outsource carefully, which parts of testing should be outsourced or what types of testing should be performed. - Informant 4

It is necessary to predict risks that might happen in advance and plan the contingency strategies to overcome them. This enables the client to be aware of the unwanted situations that might occur during the project. As outsourcing is a joint effort, the risks should cover from both client and vendor perspectives.

In terms of risks, we list out all possible risks that might happen and prepare contingency plans to handle those situations if happened. - Informant 2

By identifying or predicting the possible risks that might happen, it will help us to prepare for actions that should be taken if something happen. From our perspective as the vendor, one example is the risk of late delivery of test item. Let say, we already plan to execute the testing in certain period, however it delays because of sudden unavailability of testers, or maybe because the test environment issues that we could not avoid. We have to take actions to handle those situations. - Informant 3

Risks definitely exist in the process. For example, testers might miss out some defects unknowingly. Another example is the requirements change even after the testing has been done. So, we have to plan on how to handle these risks properly. - Informant 4

It helps us to avoid or deal with the risks if they happen. We normally look at the high risks and manage them. - Informant 5

The participants agreed that there should be a conclusive statement of work to avoid creeping scope. Determining authority is crucial as setting the person in charge within their scope of work helps clarifing their responsibility.

We should define the project scope, how many months the project will take and how much resources are needed. Statement of work contains the scope and purpose, and resources needed for the project completion. Based on the scope, then we specify what the vendor needs to deliver to us at what time or duration. - Informant 1

We have to know what tasks that the vendor should do. The statement of work declares those tasks and acts like requirements that we have set for the vendor to meet. - Informant 2

Determining statement of work and planning of whom is responsible in delivering the tasks are important. Statement of work declares the authority involved in the project. The person in charge is authorised in handling the job. - Informant 3

Client sets the statement of work for vendor and is normally referred in case there are disputes or 
confusion regarding the project scope among the vendor team members. - Informant 4

The participants acknowledged that preparing or allocating appropriate budget and resources is essential in ensuring the smooth running of the project. Resources must be allocated based on the project needs and should be properly planned in order to avoid unused or excess resources for the organisation.

We will scrutinise the budget required in order to achieve our objectives - Informant 1

The project runs because there is a need to do the project, thus proper budget planning helps to fulfill the objectives of the project. Inadequate budget allocation could cause the project to fail. - Informant 2

Preparing for budget is important. Without a capable budget, we cannot proceed to outsource. Informant 3

It is important to determine the resources needed carefully, as it should fit with the project scope and project duration. - Informant 1

We also do not want too many resources, as unutilized resources would be a waste to the company. - Informant 5

Prioritising involves determining which testing tasks should be completed first according to predetermined criteria. It is necessary for the client to prioritise the testing tasks. In contrast to the earlier theoretical study, the prioritisation is normally based on importance rather than level of difficulty. The priority also depends on which test type that brings more benefits to the client.

Prioritising can help us in ensuring that important parts are delivered in advance. Our preference is the vendor to settle the important test tasks first, regardless it is less difficult or not - Informant 2

Prioritising the work is important. Most likely, the priority is based on the importance and deadlines of the project. Therefore, which task that needs to be finished first will be our preference. - Informant 4

We prefer early testing. Client should test the software while developing it. We did priority for testing because if the testing is done only at the end of the cycle, the cost would be higher. Client should plan properly on how to prioritise so that the project would benefit them. - Informant 5

The participants felt that scheduling in respect of activities is not very critical even if the client and vendor are located far from each other. The time zone in particular does not affect the project as in principle, the schedule should consider the difference. As far as the project is concerned, the more important element in the schedule is the milestones. Especially for offshore outsourcing, the output (milestones) is more critical to the client rather than the process (activities) itself, due to time and culture differences. Based on these facts, scheduling in general still plays an essential role in software testing outsourcing.

The project may be a bit difficult due to the difference in time zone between organisations involved. But since we have project milestones, we do not really depend on scheduling per se in handling the tasks. We understand their work time and tolerate with that. - Informant 3

It is important to make sure what resources are available at what time, and plan the work schedule accordingly. Since we are dealing with other parties that have different time zone, we have to synchronise the working hours while optimizing the resources. - Informant 4

The participants agreed that planning for the infrastructure should be made before the project begins. The infrastructure plan outlines the physical materials needed for the work to be carried out by both parties. This includes setting up network and connectivity, creating version control mechanism, enabling storage and ensuring information security protection.

Before the project begins, we have to make sure that there is no problem with the infrastructure, thus allowing work to be done between our side and the vendor. Medium of communication for the participating parties must be planned earlier. The connectivity infrastructure includes official company email, virtual meeting or phone calls. - Informant 1

The network for establishing connection with client and information security policies needs to be planned to prevent unauthorised access. Planning for storage and version control is also necessary as they are needed for work management. - Informant 3

\subsection{Selecting Vendors}

The selected vendor should possess both technical and domain knowledge, has a good reputation and sufficient resources. Political stability as well as culture differences and language capability are also important. The political instability of the vendor's organisation and country could cause unnecessary interference to the project. Especially for offshore outsourcing, language and culture differences influence the communication and collaboration between client and vendor. Misunderstandings might happen along the process due to the differences. In addition, it is better to select a vendor that does not have high turnover rate to avoid the possibility of losing test team members during the project.

The participants agreed that the selection should be made based on the expertise particularly in technical and domain aspects. The client may need to provide domain experts if the selected vendor does not have sufficient domain knowledge, particularly for specific and complex business processes. 
We prefer vendors who have expertise according to what we want. We will advertise the expertise needed or obtain information from the vendors themselves regarding the skills or services that they offer. We will select a vendor that is most suitable and capable to provide the required services to us. Informant 2

Having technical testing skills is just the basic. By possessing good domain knowledge will help us as the testers to understand the project requirements better. As the testing is meant to assure the quality of software, it would not be sufficient if the testers do not know what the software is used for. - Informant 3

We are dealing with banking systems. Thus, it is important to understand the complex transaction flows and the product. If we do not have sufficient domain knowledge, we could not verify and validate the product properly. - Informant 4

Having both technical and domain expertise is beneficial and thus preferred. In some areas, the client may need to provide the domain experts. For example, oil and gas industry is a very complex and specific industry. So, such clients have to provide domain experts. This is because vendors or testers cannot be experts in every domain. - Informant 5

The participants confirmed that the reputation is also considered, as the vendor's credibility and experience assure the client to trust them in performing the project. The reputation is judged based on the vendor's establishment period or experience, previous projects' commitment and performance reports, previous customers' satisfaction levels as well as accreditation acquired or standards followed.

We will ask other companies about the vendor's profile or background, whether it is good or otherwise. For example, their performance and commitment in previous projects. - Informant 1

It is better to choose a vendor that has a good reputation, has been in the area for a long time and is well established. - Informant 2

The vendor that has a good reputation usually has the experience. They have the required services, skills and capability. It is essential to check whether the targeted vendor has a bad reputation. - Informant 4

Vendor with a good reputation should be selected. For example certain vendors follow standards such as ISO or TMMi. Those add to the reputation criteria used by the client. - Informant 5

The participants also claimed that the vendor must be able to provide sufficient resources. The resources must be available so that the agreed project schedule and objectives can be fulfilled.

Without sufficient resources, the project might take longer time or the project objectives could not be attained. - Informant 1

Sufficient resources are required to fulfill the project demands. Insufficiency of resources would affect the project duration. - Informant 2
If the vendor does not have sufficient expertise or resource, this will prolong the duration of the project. It is thus important to ensure adequate resources for the project, such as by stating in the contract, in order to avoid unsolicited things happen. - Informant 3

We have experienced having not enough resources to do a project. So, we totally agree that sufficient resources is really important. - Informant 5

The selection process also ensures the potential vendor does not experience any political instability within organisation or country.

We will take into account this aspect when examining vendors. It is a must so that we will not face any problems in terms of political stability in the vendor's organisation or country. - Informant 3

Yes, political instability is the major concern especially in global outsourcing. For instance, we have a higher chance to be selected as the vendor because our local political situation in our country is safe and we are among the developing countries. Informant 4

When cooperating with organisations outside of the country, political stability is a concern. This is because the project might be extended for many years as political disturbance affects the project progress. Informant 5

Although the participants did not face major problems with vendors from other countries, they agreed that language is important to ensure effective communication and collaboration. In fact, this element seems to be more notable than the culture difference. The participants did not support culture difference as one of the important selection criteria because it will not affect the project as long as each party can communicate, cooperate and commit in performing the assigned work.

So far for Us, we do not have much trouble in communicating even though we are from different countries. However, we agree that language plays an important role in conveying information. The cultural differences do not influence much, as long as both parties can understand and communicate well. - Informant 3

Even if you are good technically, but lack of language proficiency, it would be hard to deliver the information. For example, to explain the problems, defects or findings. That is why we think the language plays a part in the process. - Informant 5

When dealing with clients from other countries, their culture differences do not affect our collaboration. This is because both parties cooperate well in the project. The differences in culture should not be a problem as long as both parties commit in delivering the assigned work. - Informant 4

The participants approved that it influences the project success. This is because the loss of critical or experienced resources will prolong and delay the project duration. More effort and time needed for re- 
employment and training. In order to avoid this problem to occur during the project, turnover terms and conditions are considered in the contract.

The loss of resources especially experienced project members will affect the project progress. We need to re-train new members. We try to avoid this matter by defining this issue in the contract, so that we will not encounter such problems. - Informant 3

If the turnover rate is high, a lot of time will be wasted on re-training and transferring the project information to the new hires. The new hires also are less experienced and require more time to understand the project requirements. - Informant 4

We manage the turnover rate through contract, to make sure there are enough workforce on the project. - Informant 5

\subsection{Establishing the Contract}

The contract should be clear and complete, preferably in short-term duration, flexible and aligned with the project needs and plan. The content should specifically cover the scope, objectives, budget, statement of work, schedule and authority. The scope outlines what needs to be tested and what will not be tested, the objectives describe the aims of the project, the budget articulates the fund allocation and distribution as approved by the parties involved, the statement of work defines the agreed tasks in detail, the schedule specifies the timelines and milestones, and the authority statement states the personnel who hold the respective responsibility and authority. The informants agreed that developing a clear and complete contract is essential. Any ambiguity should not be in the contract.

The contract should state the conditions required for the services, the project objectives, statement of work and who have the authority, what the vendor should do to meet the terms in the contract, its scope and payment. If the contract is not complete and does not comply with the needs of the project, it would lead to disputes and misunderstanding between parties involved. - Informant 1

There should not be any doubt or confusion, which can cause problems in future. We have to specify what the vendor needs to do, at what time duration and the budget needed. - Informant 2

The contract should not contain any ambiguity statement as it will affecting the project progress. Informant 4

Once we have the customer requirements, we will provide the proposal. The proposal comes with the quotation, and if the parties involved agree with the scope and price, then we will continue with the contract. And of course, the contract should be in a clear and complete form to avoid any misunderstanding in the future. - Informant 5

There is one new element obtained from the interviews, that is, the need to include disclaimer in the contract. Disclaimer clarifies the delimitation of work scope. This element was also confirmed by [28]. Disclaimer is required in the contract as it acts as an implied warranty. For example, the implied warranty of merchantability protects the client to only receive services that conform to the client's expectations.

The contract should describe clearly what services will be provided, and disclaimer. It is important to put disclaimer in the contract to protect our services throughout the process. - Informant 5

In terms of duration, the participants also did not support that the contract should be in a short term basis. They did not believe that the duration influences the success of the project. The project success depends on how it is managed.

It is not really a concern whether it is a short or long term project, but how we manage the complexity of the project. - Informant 1

Having short-term projects might bring some benefits, but it does not mean that having a short-term contract would bring to project success. The more important is the reasonable project duration that fits with the process of the project. - Informant 2

It is not necessary that short-term contracts will lead to project success. Having short-term contracts may be beneficial, but there are possibilities that the project would still fail if it is not being managed properly. - Informant 3

Having a short-term project does not guarantee that it will succeed. The project duration depends on the project needs. It is how we control and commit to the project. - Informant 4

After signing, a contract could not be altered without legal consequences. Due to this reason, one participant noted that there is a need to have some flexibility in the contract terms. Any required adjustment can be made without however changing the original contents of the contract.

Sometimes we need to make some adjustments in the project due to circumstances that we could not avoid. If the changes are not made, there might be hard for us to achieve the project objectives. In that case, we will deal with the vendor to solve the problems. Even though there are some conditions are being changed in the process, the contract will be the same such as budget and duration in completing the work. - Informant 1

Besides that, the participants approved that the contract should be aligned with the project needs and plan that have been set earlier.

It is important to make sure that the promised work could be accomplished. The contract should follow the planned project schedule and needs. The arrangement of the contract should align with the project common goal and work process. - Informant 1

The contract should be made according to what we have planned earlier. As project plan describes what the project needs, for example effort required and project duration, the contract should be made 
according to that information in order to assure compliance to those specification. - Informant 2

Yes, it should be according to the project plan. The contract must cover for the whole project. For example, what should be delivered at the specified time and what could happen to the vendor if cannot fulfill it. - Informant 3

The contract is made to deliver the services that meet the quality expectation within the allocated time. The contract must meet the project requirements based on what have been specified in the project plan. - Informant 4

The contract should be made according to what has been set to achieve. - Informant 5

\subsection{Setting-up Infrastructure}

Infrastructure setup includes configuring network and connectivity for client and vendor to be connected. It also includes information security that should be established to ensure data or materials used for testing are secured. Apart from that, storage is needed to store the work from both parties. Besides, version control is also created at this stage. Version control setup is required as a repository to store and track the changes made to the work product. Some participants admitted that network and connectivity must be established to ensure smooth collaboration between the two parties. As testing process is dynamic, the network and connectivity configuration should be prepared before the project starts to allow sharing of information.

It is important to create mediums of communication between the parties involved. This is to ensure that the information could be delivered to the right person at the right time.- Informant 1

Because we are cooperating with people from different organisation, it is important to have mediums of connection with them. The connection should be developed at early stages of the project as it helps to provide channels to share information between people involved. For example, company instant messaging, email and telephone are among communication channels that we use to create connections with the vendor. - Informant 2

Without establishing the network infrastructure, communication is impossible. We also make sure we get the access before beginning the testing process. Setting infrastructure is important before starting the testing phase, and maintaining the infrastructure is a continuing process throughout the project. Informant 3

We have our IT people, who are the communication team that will do the set up. They do the set up based on the project needs. The configuration includes internet connection, virtual private network or granting secure access for file sharing. - Informant 4

Most participants agreed that it is necessary to secure the shared information since the project involves two different organisations. Improper information security controls could jeopardise the client's information and assets. Among the controls that require attention include data confidentiality and access, intranet access to external, firewalls and virtual private networks.

We need to test over the test environment, the access, the IP and what we could release to the vendor. We can put these into security measures to ensure the information is secured. - Informant 1

As the vendor team, we must have well established security standards and measures in place to prevent unauthorised access and misuse of the client's information. In order to protect those data, we usually sign a non-disclosure agreement with the client. - Informant 3

We have a secured room where we keep the confidential data. Only the authorised person will be able to access the room, in fact, in a specific period of time. - Informant 5

Since the parties involved come from different organisations, the participants acknowledged that storage is a part of the infrastructure set-ups needed. Storage is required for archiving and distributing testing materials and artifacts during the process. The types of storage are not limited to digital storage only but also physical storage for testing materials.

We need to store materials used throughout the project. We transfer our materials to the vendor by using separate disks and pluck them at different locations. The vendor use the disks to access the required information and store the testing materials. Informant 2

Normally companies use digital storage and testing tools to store testing materials, for example, HPQC. Informant 4

We keep either as hardcopy or softcopy. We have some software to handle softcopy materials, which are stored in the server, thus they are definitely protected by the access control. For hardcopy, we have specific procedures for storing those materials. We also provide a secure room for storing project sensitive documents. Only the authorised person is allowed to enter the room within specified duration. Informant 5

The participants also agreed that version control should be established for recording and tracking the changes during the testing process. The version control tools should store and keep track the changes of not only testing materials but also project documents.

We use software to track and record the document versions and project progress. - Informant 2

Everything could be placed under the version control software and this makes it easy to follow and detect the changes that are taking place. - Informant 3

Yes, it is also important to have a version control setup over the project progress. It allows the parties involved to have the access to the latest testing materials at the current time. - Informant 4 
Project stakeholders can get updates about the project progress through current versions available in the version control tools. - Informant 5

\subsection{Preparing for Testing Phase}

Testing preparation phase comprises the activities of organising the testing environment. In order for the vendor to perform testing, requirements specification and test materials or artifacts need to be acquired from the client, which are used to prepare the test plan. The plan is then reviewed and approved by the client. Based on the test plan, the test environment is prepared. Test standardisation process and tools are also prepared to syncronise the work from both parties. This factor was introduced by the participants of the empirical study and supported by [15].

We submit the related documents, for example Software Requirements Specification (SRS), to the vendor. They use them as the preparation to do testing. They draft the test plan, the technologies to be used and the schedule. - Informant 1

The submission of the requirements specification helps us to identify test requirements and plan for testing process that will be conducted. - Informant 3

It is important to gather and identify the requirements used during the development from the client. It is important to cover all requirements in the test plans and test cases. - Informant 5

A test plan is usually prepared by the test leader or test manager. Preparing a test plan includes linking requirements to testing effort, determining the quality objectives, assessing risks and estimating resources needed based on the testing schedule and workload. The test plan should thus be detailed as possible, as it must cover major components to direct the testing process.

The test plan will be developed by the test leader. As testers, the test plan is important as it is used to guide the testing later. The test plan includes basic tasks in testing cycle for example test requirements, test cases, risks and test execution.-Informant 3

It is important to make sure that we develop the test plan thoroughly, according to what it is intended. The test plan should clarify the work schedule and test equipment needed. - Informant 4

Producing test plan is important for the testing phase preparation as it describes the scope of the overall test effort that will be performed and what the testing team needs to prepare to meet the needs of the client. - Informant 5

Test environment should be prepared before executing the tests and managed throughout the testing process. It is important to ensure that the test environment is completely ready before executing the testing operations. The readiness of test environment basically involves network, hardware such as servers and software such as operating systems needed to perform the tests. The test environment must represent closely the actual production environment.

To ensure the test environment is properly set is important. Sometimes we could not resolve the sdefects and keep on being rejected because of test environment issues. It is time consuming. The test environment has to be configured and managed properly to meet the identified test goals for the system under test. - Informant 3

We have to make sure that the test environment is similar to the production environment, as the tested product will be released at its actual production environment later on. Improper test environment configuration would cause the system or software under test to behave differently. It is difficult and time consuming to trace what is wrong. - Informant 4

We have a dedicated provisioning group to test the environment for us to do the testing. After the testing materials have been handed over to the vendor, we will do the 'smoke test' to verify that the testing environment is ready. We will simulate the environment, install the application or system to run the test - Informant 5

A toolset for test standardisation is introduced to organise the testing process. The standardisation includes the integrated testing environment and supporting tools that encapsulate business knowledge and functional aspects between the parties involved. Most informants claimed that standardisation of test process and tools help the project to run smoothly.

Normally companies have standard procedures to syncronise practices by other organisations. Since we are cooperating with different teams and organisations, standardisation is important to increase process efficiency and enhance project control. The parties involved must follow the designated steps in the standard process. For example we have standard checklist to ensure required procedure are followed. - Informant 4

Standardisation helps to meet the project requirements, as it supports the methodology and quality process. - Informant 5

\subsection{Monitoring Testing Execution}

Testing execution involves performing testing activities through validation and verification activities. The execution can be either manual or automated testing. In each type of testing performed, there would be a set of requirements, schedules and specific procedures that must be followed. Hence, it is important to manage and control the activities properly. This is done through project monitoring.

Project monitoring involves activities to observe the work progress during the execution of testing. The mechanisms include regular visits, project progress reports, discussions, reminders of project objectives and on-site representative. The participants agreed that the mechanisms help in monitoring the project 
progress and status. By having discussions and progress reports periodically, the testing execution can be monitored from time to time and any problems that occur could be resolved immediately. By having regular visits and on-site representative, the testing progress can be observed and controlled such as whether or not the project goes according to schedule, has adequate resource and fulfills the deliverables. Reminders help to point out the project objectives from time to time and highlight any pending tasks that should be done, which will affect the project progress if they are deferred. The participants agreed with the fact that active ongoing discussions assist in achieving better management for outsourcing projects.

Discussion helps to monitor the project progress, resolves any issues and requested changes. The joint venture between both parties is not easy to manage, as changes in planning might happen under certain circumstances.-Informant 1

Through these meetings and discussions, we will know for example if there is a problem or there is a need to extend the duration of the project, and solve the problems. - Informant 2

We need to know whether we are delivering the right thing to the client and fulfilling their expectations. From discussions, we are able to discover any problem that occurs throughout the project and find ways to solve it. - Informant 5

The participants also agreed that regular progress reports help to ensure the project to be on the right track. They also advocated that reminders are important for recalling project objectives and avoiding schedule delays. Reminders are given by client during the meetings of project progress report.

Through progress reports, the vendor shows the actual states of the progress. It may not be same if it is mentioned through verbal communication. Informant 1

Progress report enables transparency in information and project status for both client and vendor and helps to gauge whether there is any problem throughout the process. - Informant 2

Reporting through progress reports is beneficial as it shows project accomplishments by specific dates. Through project progress reports, the status of milestones could be known for example which one is still in progress or which one is already finished. Informant 3

Through progress reports, the client is reassured that vendor is making progress and the project could be completed within the expected time.- Informant 4

We usually will remind the vendor about the project objectives during meetings and discussions, or when we are revising the project requirements.-Informant 1

We will have reminders for example if there is any delay in work progress. We will remind the people involved to solve the problem, so that it will not prolong the duration. - Informant 5

On-site representative and regular visits are also useful in monitoring the project progress, besides maintaining the relationship between both parties. With the presence of on-site representative in particular helps to coordinate and smooth up the operations.

Regular visits is important in order to know how the vendor team operates. Performing regular visits helps to maintain the relationship with the vendor and monitoring the work performed. - Informant 2

On-site visits and representative are needed. Particularly if the parties involved are located away from each other, the role of on-site representative and regular visits is very important to coordinate and control the project. - Informant 3

The presence of client representative is beneficial to give clearer information of their product. Besides that, the client production team is needed in order to install and configure the test environment to make sure it is similar to the client development environment. - Informant 4

Test lead monitors the project progress to make sure it runs according to the schedule, resources and deliverables. However, there should be a representative from the client side because this project is theirs. They have the knowledge of how to derive the work better. - Informant 5

\subsection{Conducting Quality Assessment}

Quality assessment concerns evaluating the quality of testing performed by the vendor. The client checks or confirms whether the work done has met the agreed requirements. If the vendor has fulfilled the client's needs, the work can be signed off. The corrective actions have to be taken if the work is rejected. This decision is mainly made by the client based on the test reports produced by the vendor. The reports contain the summary of test activities and the final test results. The participants generally approved this factor.

We are implementing quality assessment to evaluate the work performed by the vendor. If the results are not satisfying, we will request the vendor to repeat the testing until the expected results are achieved. Informant 1

Quality assessment is important because this is when we will evaluate the results of the testing. The vendor will collaborate closely with our product team. The product team will assess the testing results obtained. - Informant 3

After we have completed the testing, we will submit the report and the client will check randomly the testing. The client will decide based on the test results. If the results satisfy the requirements, the client will sign-off. - Informant 4 
Table 3 Process Factors and Elements for Software Testing Outsourcing Implementation

\begin{tabular}{|c|c|c|c|}
\hline Factor & Elements/Criteria/Characteristics & Literature & $\begin{array}{l}\text { Individual } \\
\text { Interview }\end{array}$ \\
\hline \multirow[t]{3}{*}{$\begin{array}{l}\text { Needs } \\
\text { Identification }\end{array}$} & $\begin{array}{l}\text { Client should determine the purpose of pursuing testing outsourcing (i.e. quality } \\
\text { concerns). }\end{array}$ & / & $/(4 / 5)$ \\
\hline & $\begin{array}{l}\text { Client must have specific reasons to outsource testing (i.e. knowledge, resource } \\
\text { or cost constraint). }\end{array}$ & / & $/(4 / 5)$ \\
\hline & $\begin{array}{l}\text { Client should understand the nature of outsourcing (i.e. strengths, limitations, risks } \\
\text { and expectations). }\end{array}$ & / & $/(3 / 5)$ \\
\hline \multirow{9}{*}{$\begin{array}{l}\text { Project } \\
\text { Planning }\end{array}$} & Client plans its objectives and goals for testing outsourcing project. & / & $/(4 / 5)$ \\
\hline & $\begin{array}{l}\text { Client should determine testing types to be outsourced and test artifacts to be } \\
\text { given. }\end{array}$ & / & $/(3 / 5)$ \\
\hline & $\begin{array}{l}\text { Contingency plan for both client and vendor sides must be prepared to } \\
\text { overcome possible risks in testing outsourcing. }\end{array}$ & / & $/(4 / 5)$ \\
\hline & $\begin{array}{l}\text { Scope and statement of work for testing should be defined clearly together with } \\
\text { authority/roles and responsibility. }\end{array}$ & / & $/(4 / 5)$ \\
\hline & $\begin{array}{l}\text { Resources should be allocated according to project needs to ensure proper } \\
\text { utilisation. }\end{array}$ & / & $/(2 / 5)$ \\
\hline & $\begin{array}{l}\text { Budget must be planned appropriately based on the nature of testing } \\
\text { outsourcing. }\end{array}$ & / & $/(3 / 5)$ \\
\hline & Testing tasks should be prioritised based on importance and benefits to client. & / & $/(3 / 5)$ \\
\hline & $\begin{array}{l}\text { Scheduling should be planned properly by optimising resources and time zone } \\
\text { difference. }\end{array}$ & / & $/(3 / 5)$ \\
\hline & $\begin{array}{l}\text { Infrastructure planning for network and connectivity, version control, information } \\
\text { security policy and storage need to be carried out before setting-up. }\end{array}$ & / & $/(3 / 5)$ \\
\hline \multirow[t]{6}{*}{$\begin{array}{l}\text { Vendor } \\
\text { Selection }\end{array}$} & $\begin{array}{l}\text { Vendor has a good reputation in terms of experience, credibility and capability } \\
\text { in performing testing. }\end{array}$ & / & $/(4 / 5)$ \\
\hline & Vendor should possess technical and domain knowledge & / & $/(4 / 5)$ \\
\hline & $\begin{array}{l}\text { Vendor has sufficient resources throughout the project duration. } \\
\text { Politics in vendor's organisation and country are stable. }\end{array}$ & / & $\begin{array}{l}/(4 / 5) \\
/(3 / 5)\end{array}$ \\
\hline & The language used by vendor to communicate. & / & $/(5 / 5)$ \\
\hline & Culture in vendor's organisation or country. & / & $\times(0 / 5)$ \\
\hline & Turnover rate in vendor's organisation. & / & $/(3 / 5)$ \\
\hline \multirow[t]{5}{*}{$\begin{array}{l}\text { Contract } \\
\text { Establishment }\end{array}$} & $\begin{array}{l}\text { Contract should be clear and complete, (i.e. scope, objective, budget, } \\
\text { statement of work, schedule and authority). }\end{array}$ & / & $/(4 / 5)$ \\
\hline & $\begin{array}{l}\text { Disclaimer in contract clarifies the delimitation of work scope and acts as an } \\
\text { implied warranty. }\end{array}$ & / & $/(1 / 5)$ \\
\hline & Contract should be flexible as an effort to fulfill project objectives. & / & $/(1 / 5)$ \\
\hline & Contract should be in short term basis. & / & $\times(0 / 5)$ \\
\hline & Contract should be aligned with the project plan and needs. & / & $/(4 / 5)$ \\
\hline \multirow[t]{4}{*}{$\begin{array}{l}\text { Infrastructure } \\
\text { Setup }\end{array}$} & $\begin{array}{l}\text { Network and connectivity should be setup beforehand for communication } \\
\text { purposes. }\end{array}$ & / & $/(5 / 5)$ \\
\hline & Information security mechanisms should be established to secure data. & / & $/(3 / 5)$ \\
\hline & $\begin{array}{l}\text { Storage is required for archiving and distributing testing materials and artifacts } \\
\text { during the process. }\end{array}$ & / & $/(3 / 5)$ \\
\hline & $\begin{array}{l}\text { Version control setup should be established for recording and tracking the } \\
\text { changes during the testing process. }\end{array}$ & / & $/(4 / 5)$ \\
\hline \multirow[t]{4}{*}{$\begin{array}{l}\text { Testing Phase } \\
\text { Preparation }\end{array}$} & $\begin{array}{l}\text { Vendor should acquire requirements specification and test artifacts/materials } \\
\text { from client to prepare test plan. }\end{array}$ & / & $/(3 / 5)$ \\
\hline & $\begin{array}{l}\text { Test plan should be detailed by covering the essential components to direct the } \\
\text { testing process. }\end{array}$ & / & $/(3 / 5)$ \\
\hline & $\begin{array}{l}\text { Test environment needs to be completely ready and tested before executing } \\
\text { the testing operations. }\end{array}$ & / & $/(3 / 5)$ \\
\hline & $\begin{array}{l}\text { Test standardisation tools and procedure are imposed to systematise the testing } \\
\text { process. }\end{array}$ & / & $/(2 / 5)$ \\
\hline \multirow[t]{4}{*}{$\begin{array}{l}\text { Project } \\
\text { Monitoring }\end{array}$} & $\begin{array}{l}\text { Active and on-going discussion should be done frequently to confer any issues } \\
\text { or adjustments. }\end{array}$ & / & $/(3 / 5)$ \\
\hline & Project progress should be reported timely to keep the project on the right track. & / & $/(4 / 5)$ \\
\hline & Client representative is available at the site to monitor the project progress. & / & $/(2 / 5)$ \\
\hline & $\begin{array}{l}\text { Client should made regular visits to help coordinating the operations besides } \\
\text { fostering the relationship. }\end{array}$ & / & $/(1 / 5)$ \\
\hline $\begin{array}{l}\text { Quality } \\
\text { Assessment }\end{array}$ & $\begin{array}{l}\text { Test reports are used to communicate the test activities and results to project } \\
\text { stakeholders for approval. }\end{array}$ & / & $/(4 / 5)$ \\
\hline \multirow[t]{2}{*}{$\begin{array}{l}\text { Project Close- } \\
\text { Out }\end{array}$} & $\begin{array}{l}\text { Vendor's performance throughout the project is assessed for closure and future } \\
\text { opportunities. }\end{array}$ & / & $/(3 / 5)$ \\
\hline & Vendor hands over the project artifacts back to client. & / & $/(3 / 5)$ \\
\hline
\end{tabular}


We conduct a customer satisfaction survey to evaluate the testing quality. It is used to check whether the client is satisfied with the test coverage. It is important because from there we could capture what went wrong, if any - Informant 5

\subsection{Managing Project Close-Out}

Project close out is executed at the end of software testing outsourcing process after the client is satisfied with the outcomes. The client assesses the vendor's overall performance and hands over the testing materials back to the client. This includes hardcopy, softcopy or any applications that were stored at the vendor's site. The participants acknowledged that executing vendor assessment is necessary to evaluate their performance throughout the testing outsourcing process.

Yes, vendor assessment is performed at the end of the process in order to measure the vendor's performance. The evaluation is made based on certain criteria that has been set, for example, their on-time delivery level, service level or how they handle unexpected changes. The assessment is important in order to determine whether the vendor is meeting the preset performance level. This helps the client to make future decision. - Informant 1

The assessment is mostly made based on what level we as the vendor is able to provide and deliver to the client. Implementing vendor assessment is important as it helps us to improve our performance based on that evaluation. - Informant 3

The vendor performance will be evaluated by how fast they could finish the tasks. It means that how much the testing team could do in certain period of time. The working pace is used to indicate the vendor performance. - Informant 4

The participants also claimed that project artifacts including both hardcopy and softcopy materials owned by the client must be returned or removed from the vendor's properties.

At the end of the process, we have to make sure that our properties are transferred back to us. This is important to protect our resources as those materials contain valuable information. - Informant 1

There is a sign-off document. The client checks and only signs it off if everything has been completed and sent back to them. - Informant 3

We return the materials that belong to the client. This includes software and hardware for example removing the client's applications from our system and handing over testing artifacts such as test cases.-Informant 4

\subsection{Roles and Responsibility}

Top management is responsible in giving the direction to the project from the organisational perspective. Project manager is responsible in managing the project, possess good interpersonal skills to manage social gaps between the parties involved due to culture and language differences. Members from project and test teams should cooperate, commit, willing to share knowledge and instilling partnership values. The participants agreed that without proactive top management, project manager and teams, a successful software testing outsourcing project might be difficult to achieve.

We need the support from top management for example in terms of budget. We need a qualified project manager to liaise with the involved parties and cooperative teams to do the tasks assigned. Informant 1

Top management has to know the direction, project progress and give support. If they do not support and do not know what happen to the project, then it will be difficult. Project manager must know how to manage the project resources and timeline and have to possess good interpersonal skills.-Informant 5

A presentable project manager is important in order to deal with different groups of people in the project. - Informant 2

Project manager is responsible to coordinate us with the client organisation. We will inform the project manager if there is an unexpected problem that needs attention or further action. - Informant 4

Project team members are mainly software developers who produce and maintain project artifacts. To ease work transmission and interchange between two organisations, project team members must cooperate, commit, trust, bring partnership and good relationship values to test team members. The participants confirmed these facts.

We need to work together and want to achieve the same objectives and mutual benefits. Cooperation could be shown through our communication and support in dealing the tasks assigned. - Informant 1

We have to cooperate well in order to accomplish the tasks. We want to get good results, so we need to maintain good relationship with the other party. Besides, trust is also necessary. The vendor has the access to some of our valuable materials and assets. They sometimes make mistakes or have problems that could affect us. It is important to build trust and work on how to manage the issues. - Informant 2

Each team member has to manage their time, so that we are able to meet the milestones, so that the project could be finished according to the schedule. - Informant 3

Yes, building good relationship is important in the joint venture process. Cooperation and partnership values as humans strengthen the joint venture rather than depend solely on contract relationship. Informant 4

We need to share knowledge and resources with the other party, thus developing partnership is important to ease the process. Partnership could deepen and strengthen the relationship as it also may lead to other projects in the future. - Informant 5 
Good communication skills is also crucial in conveying information between project and test teams to avoid misunderstanding.

Communication is important as the process does not only involve technical aspects, it requires information passing between organisations.-Informant 5

We need to inform the status of our tasks to the leader. It is important to make sure that he/she understands well our progress and the difficulties that we face. - Informant 3

As we need to cooperate with the other organisation, having good communication is crucial to deliver the information or to convey the project progress to the client. How we deliver the information adds to the quality of our service. - Informant 4

The teams also should tolerate and understand each other well. As the domain experts, project team members must be willing to share their knowledge with test team members.

They also should tolerate and understand each other in order to perform the work well. If the testers accidently did mistake, the effort could still be appreciated through tolerance and understanding. Informant 4

We syncronise our working hours with the workload in order to achieve the project milestones, due to time zone difference. Sharing knowledge is also necessary as we are doing work for another company, which domain might be unfamiliar to us.Informant 3

The test team consists of testers, is led by a test leader. Testers execute the testing whereas test leader monitors the progress and results. Test leader cooperates and liaises with project manager in managing the project. Testers should be knowledgeable, skillful, professional pessimistic and attentive to details besides having curiosity and critical eye in order to discover and scrutinise defects.

Testers must have the required knowledge and skills in doing the testing. - Informant 3

Test leader works closely with testers to monitor their work progress as well as control the testing activities and outcomes. It is important to manage the testing execution properly to ensure the functionality and quality of the product under test. - Informant 4

Testers should have curiosity, critical eye, being attentive to details, professional pessimistic to find defects and foresee what could be wrong to detect any possible defects during the testing. - Informant 5

Table 4 People Factors and Elements for Software Testing Outsourcing Implementation

\begin{tabular}{|c|c|c|c|}
\hline Factor & Elements/Roles and Responsibilities & Literature & $\begin{array}{l}\text { Individual } \\
\text { Interview }\end{array}$ \\
\hline $\begin{array}{l}\text { Top } \\
\text { Management }\end{array}$ & $\begin{array}{l}\text { Top management should give full commitment in ensuring the project is always on } \\
\text { track. }\end{array}$ & / & $/(2 / 5)$ \\
\hline $\begin{array}{l}\text { Project } \\
\text { Manager }\end{array}$ & $\begin{array}{l}\text { Project manager should possess interpersonal skills to handle differences (i.e. } \\
\text { distances, culture, language and time zone). }\end{array}$ & / & $/(4 / 5)$ \\
\hline \multirow[t]{7}{*}{ Project Team } & $\begin{array}{l}\text { Full cooperation should be given to ensure smooth operations between parties and } \\
\text { partnership values should be instill instead of merely contract-based relationship. }\end{array}$ & / & $/(5 / 5)$ \\
\hline & Commitment should be given to make sure the project is according to schedule. & / & $/(1 / 5)$ \\
\hline & Trust should be present. & / & $/(1 / 5)$ \\
\hline & $\begin{array}{l}\text { Good relationship is highly required in collaborating teams from different } \\
\text { organisations. }\end{array}$ & / & $/(4 / 5)$ \\
\hline & Good communication should be practiced in order to streamline the process. & / & $/(3 / 5)$ \\
\hline & Tolerance and understanding should be practised to ease the work process. & / & $/(2 / 5)$ \\
\hline & $\begin{array}{l}\text { Knowledge transfer and sharing should be practised to ensure better information } \\
\text { flow. }\end{array}$ & / & $/(1 / 5)$ \\
\hline \multirow[t]{10}{*}{ Test Team } & $\begin{array}{l}\text { Test Leader monitors the testers' work progress closely and controls the testing } \\
\text { activities. }\end{array}$ & / & $/(1 / 5)$ \\
\hline & Tester should possess technical and domain skills. & / & $/(1 / 5)$ \\
\hline & $\begin{array}{l}\text { Tester should possess tester attributes such as professional pessimism, curiosity, } \\
\text { attentive to details and critical eye to find defects. }\end{array}$ & / & $/(1 / 5)$ \\
\hline & $\begin{array}{l}\text { Full cooperation and partnership value should be given in order to ease the } \\
\text { collaboration with project team }\end{array}$ & / & $/(5 / 5)$ \\
\hline & Commitment should be given to make sure the project is according to schedule. & / & $/(1 / 5)$ \\
\hline & Trust should be present. & / & $/(1 / 5)$ \\
\hline & $\begin{array}{l}\text { Good relationship is highly required in collaborating teams from different } \\
\text { organisations. }\end{array}$ & / & $/(4 / 5)$ \\
\hline & Good communication should be practiced in order to streamline the process. & / & $/(3 / 5)$ \\
\hline & Tolerance and understanding should be practised to ease the work process. & / & $/(2 / 5)$ \\
\hline & $\begin{array}{l}\text { Knowledge transfer and sharing should be practised to ensure better information } \\
\text { flow. }\end{array}$ & I & $/(1 / 5)$ \\
\hline
\end{tabular}




\subsection{DISCUSSION AND CONCLUSION}

The empirical study has confirmed that most factors found in the literature are indeed practised in the industry and relevant to the context of successful software testing outsourcing projects. In comparison to the results of previous theoretical study [7], there are several new factors and elements added in both Process and People category. For Process category, the new factor added is Testing Phase Preparation meanwhile disclaimer is the new element considered in Contract Establishment factor. People category includes two new factors, namely Test Team and Project Team, which have been refined further from the theoretical study. Since both teams still need to work as one unified group, they have similar elements except that Test Team factor contains tester attributes. However, there are also several elements from the theoretical study that are not supported by the empirical study. For instance, most participants did not support culture as an important criterion to be considered in selecting vendors. Culture difference can be tolerated as long as the project objectives are fulfilled. The participants also disagreed that the contract should be in short-term basis. This is because the success of a project depends on its management rather than duration. The analysis also has discovered that some elements need to be repositioned, renamed or even deleted. For instance, reminders are more suitable to be considered under progress reports, rather than standing by its own. Version control setup was originally placed in Project Close Out factor, however it has been relocated under Infrastructure Setup factor. This is because the work product versions can only be compiled at the end of the project if the setup has taken place earlier. For Quality Assessment factor, the element has been renamed as test reports instead of validation and verification, as the term may mislead the testing community. Reusable tools element has been deleted from Infrastructure Setup factor, as its influence towards the success software testing outsourcing is unclear.

This paper has discussed the contributing success factors of software testing outsourcing projects, which have been collated through theoretical and empirical perspectives. The factors were gathered qualitatively from literature reviews and individual interviews involving five practitioners from software testing industry. Most factors and elements exist in both studies. There are also several factors and elements that were found in only one of the studies or not firmly supported. Being a qualitative study, these factors are still considered as valid to the results as they have been discovered by at least one study or informant. However, these findings can be strengthened and refined further by confirming the factors and elements qualitatively with experts and quantitatively through a survey with wider samples. The findings can then be used to formulate a solid framework for successful software testing outsourcing projects.

\section{Acknowledgement}

The authors thank the practitioners who participated in the study.

\section{References}

[1] Lu, Y. and Kakola, T. 2011. Which Test Artifacts Testing Service Providers should Reuse and How? Experiences from a Case Study in the Chinese ICT Sourcing Market. Proceedings of the 44th Hawaii International Conference on System Sciences. 1-10.

[2] Bertolino, A. and Faedo, I. A. 2007. Software Testing Research: Achievements, Challenges, Dreams Software Testing Research: Achievements, Challenges, Dreams. Future of Software Engineering(FOSE'07) IEEE 2007.

[3] Poston, R., Simon, J., and Jain, R. 2014. Managing Offshore Outsourcing of Software Testing. umdrive.memphis.edu. [Online]. From: https://umdrive.memphis.edu/gmis/www/memphis/step/documents/papers/PostonR.step -07.pdf [Acessed on 1 Feb 2014].

[4] Tervonen, I., Haapalahti, A., Harjumaa, L., and Simila, J. 2013. Outsourcing Software Testing: A Case Study in the Oulu Area. 2013 13th Int. Conf. Qual. Softw. July 2013. 6574.

[5] Ahmed A. M. and Zhu. W. 2011. Outsourcing Software Testing Activities: A Case Study for Eastern Ocean Solutions (EOS)-China. 2011 IEEE 3rd Int. Conf. Commun. Softw. Networks. May 2011. 742-744.

[6] Bourne, V. 2013. The Problems of Outsourcing Application Development and Testing-Micro Focus October 2013 [Online].From:http://www.microfocus.com/_ex/borland/a ssets/reports/Vanson-Bourne-testing-research-results.pdf. [Acessed on 30 Disember 2014].

[7] Ismail, F. F. and Razali, R. 2014. Contributing Factors of Successful Software Testing Outsourcing. 2014 8th Malaysian Software Engineering Conforence. 55-60.

[8] Herath, T. and Kishore, R. 2009. Offshore Outsourcing: Risks, Challenges, and Potential Solutions. Information System Management. 26(4): 312-326.

[9] Abdullah, L. M. and Verner, J. M. 2012. Analysis and Application of an Outsourcing Risk Framework. Journal System Software. 85(8): 1930-1952.

[10] Hanna, R. and Daim T. 2007. Critical Success Factors in Outsourcing: Case of Software Industry. Management of Engineering and Technology, Portland International Center:1456-1465.

[11] Pei, Z., Zhen-xiang, Z., and Chun-ping, H. 2008. A Framework for IT Outsourcing Decision Process. Service Systems and Service Management. 1-4.

[12] Tervonen. I. 2009. Offshoring Test Automation: Observations and Lessons Learned. Fourth IEEE International Conference on Global Software Engineering Offshoring. 226-235.

[13] Shah, H., Sinha, S., and Harrold, M. J. 2011. Outsourced, Offshored Software-Testing Practice: Vendor-Side Experiences. 2011 IEEE Sixth International Conference on Global Software Engineering. August 2011. 131-140.

[14] Ghag, A. 2008. Case Study: Testing for Utilities Sector. Rightshore! Springer Berlin Heidel. 187-201.

[15] Lu, Y. 2010. A Dynamic Life-Cycle Model For The Provisioning Of Software Testing Services: Experiences From A Case Study In The Chinese Ict Sourcing Market. 112.

[16] Yalaho A. and Nahar N. 2010. Key Success Factors for Managing Offshore Outsourcing of Software Production Using The ICT-Supported Unified Process Model: A Case Experience from Finland, India, Nepal And Russia. Technology Management for Global Economic Growth (PICMET), 2010 Proceedings of PICMET. 10: 1-14. 
[17] Nicholson, B. and Sahay, S. 2001. Some Political and Cultural Issues in the Globalisation of Software Development: Case Experience From Britain and India. Information and Organization Elsevier Science Ltd. 25-43.

[18] Nakatsu, R. T. and lacovou, C. L. 2009. A Comparative Study of Important Risk Factors Involved in Offshore and Domestic Outsourcing of Software Development Projects: A Two-Panel Delphi Study. Information \& Management. Elsevier. 46(1): 57-68.

[19] Khan, S. U., Niazi, M., and Ahmad, R. 2009. Critical Barriers for Offshore Software Development Outsourcing Vendors: A Systematic Literature Review. 2009 16th Asia-Pacific Software Engineering Conference. December 2009: 79-86.

[20] Shah, H., Harrold, M. J., and Nersessian, N. J. 2011. Studying the Influence of Culture on Outsourced Offshored Software-Testing Practice: An Ethnographic Approach. 2011 IEEE Sixth International Conference on Global Software Engineering Workshop. August 2011: 105107.

[21] Khan, A. W. and Khan, S. U. 2013. Critical Success Factors for Offshore Software Outsourcing Contract Management from Vendors' Perspective: An Exploratory Study Using A Systematic Literature Review. IET Software. Dec. 2013. 7(6): 327-338.

[22] Li, J., Ma, J., Conradi, R., Chen, W., Ji, J., and Liu, C. 2007. A Survey on the Business Relationship between Chinese Outsourcing Software Suppliers and Their Outsourcers. 14th Asia-Pacific Software Engineering Conference (APSEC'07). December 2007: 470-477.

[23] Oza, N., Hall, T., Rainer, A., and Grey, S. 2004. Critical Factors in Software Outsourcing: A Pilot Study. ACM Workshop on Interdisciplinary Software Engineering Research, WISER. 67-71.

[24] Xi-feng, S., Rong, D., and Shi-zhong, A. 2011. Relationship Quality, Knowledge Sharing and Outsourcing Performance in Information Technology Outsourcing. Management and Service Science (MASS), 2011 International Conference. 1-4.

[25] Nguyen, P. T., Babar, M. A., and Verner, J. M. 2006. Critical Factors in Establishing and Maintaining Trust in Software Outsourcing Relationships. 624-627.

[26] Khan, S. U., Imtiaz, S., Niazi, M., Bano, M., and Ikram, N. 2013. Establishing Trust in Offshore Software Outsourcing
Relationships: An Exploratory Study Using A Systematic Literature Review. IETSoftware. 7(5): 283-293.

[27] Taipale, O., Karhu, K., and Smolander, K. 2007. Observing Software Testing Practice from the Viewpoint of Organizations and Knowledge Management. First International Symposium on Empirical Software Engineering and Measurement (ESEM 2007). September 2007: 21-30.

[28] Kaner, C. 2000. An Outline for Software Testing Outsourcing. Jain.

[29] Poston, R., Simon, J., and R. 2010. Client Communication Practices in Managing Relationships with Offshore Vendors of Software Testing Services. Communication of the Association for Information Systems. 27: 129-148.

[30] Jones, J., Grechanik, M., and Van der Hoek, A. 2009. Enabling and Enhancing Collaborations Between Software Development Organizations and Independent Test Agencies. Cooperative and Human Aspects on Software Engineering, 2009. CHASE '09. ICSE Workshop. 5659

[31] Andaloussi, B. S. and Braun, A. 2006. A Test Specification Method for Software Interoperability Tests in Offshore Scenarios: A Case Study. IEEE International Conference on Global Software Engineering (ICGSE'06).

[32] Choi, M., Brand, M., and Kim, J. 2009. A Feasibility Evaluation on the Outsourcing of Quality Testing and Inspection. International Journal of Project Management. 27(1): 89-95

[33] Casey, V., Richardson, I., and HAodha, M. Ó. 2009. Software Testing and Global Industry. Cambridge Scholars Publishing.

[34] Clott, C. 2007. An Uncertain Future: A Preliminary Study of Offshore Outsourcing from the Manager's Perspective. Management Research News. 30(7): 476-494.

[35] Jain, R. P., Poston, R. S., and Simon, J. C. 2011. An Empirical Investigation of Client Managers' Responsibilities in Managing Offshore Outsourcing of Software-Testing Projects. IEEE Transactions on Engineering Management. November 2011 . 58(4): 743-757.

[36] Flick, U. 2010. An Introduction To Qualitative Research. London: SAGE Publications Ltd. Fourth Edition.

[37] Krippendorff, K. 2013. Component of Content Analysis, in Content Analysis: An Introduction to its Methodology. 3rd Edition. Los Angeles: SAGE Publication. 